ORIGINAL ARTICLE

\title{
Characterization of porcine oocytes stained with Lissamine Green B and their developmental potential in vitro
}

\author{
Alexandra Bartkova ${ }^{1,2}$ (D), Martin Morovic ${ }^{1}$ (D), Frantisek Strejcek ${ }^{1 *}$ (D), Matej Murin ${ }^{2}$ (D), Michal Benc ${ }^{1}$ (D), \\ Florina Popovska Percinic ${ }^{3}$ (D) Jozef Laurincik ${ }^{1,2}$ (D) \\ ${ }^{1}$ Faculty of Natural Sciences, Constantine the Philosopher University in Nitra, Nitra, Slovak Republic \\ ${ }^{2}$ Institute of Animal Physiology and Genetics, Czech Academy of Sciences, Libechov, Czech Republic \\ ${ }^{3}$ Faculty of Veterinary Medicine, Ss. Cyril and Methodius University in Skopje, Skopje, Republic of North Macedonia
}

How to cite: Bartkova A, Morovic M, Strejcek F, Murin M, Benc M, Percinic FP, Laurincik J. Characterization of porcine oocytes stained with Lissamine Green B and their developmental potential in vitro. Anim Reprod. 2020;17(4):e20200533. https://doi.org/10.1590/1984-3143-AR2020-0533

\begin{abstract}
Traditional methods for the evaluation of oocyte quality are based on morphological classification of the follicle, cumulus-oocyte complex, polar body and meiotic spindle. This study is focused on the differences between the morphological assessment of oocyte quality, the assessment based on Lissamine Green B (LB) staining and the analysis of oocytes using a proteomic approach. We evaluated the effectiveness of electrochemical and chemical parthenogenetic activation under our laboratory conditions and evaluated the applicability of Lissamine Green B staining of cumulus-oocyte complexes (COCs) as a non-invasive method for predicting the maturational and developmental competence of porcine oocytes cultured in vitro. We determined that chemical parthenogenetic activation using ionomycin and 6-dimethylaminopurine was slightly more effective than electrochemical activation. After oocyte selection according to LB staining, we found significant differences $(P<0.05)$ between the LBgroup and LB+ group and the control group in their maturation, cleavage rate and rate of blastocysts. Proteomic analyses identified a selection of proteins that were differentially expressed in each group of analysed oocytes. Oocytes of the LB- group exhibited an increased variability of proteins involved in transcription regulation, proteosynthesis and the protein folding crucial for oocyte maturation and further embryonic development. These results found a better competence of LB- oocytes in maturation, cleavage and ability to reach the blastocyst stage.
\end{abstract}

Keywords: pig, oocyte quality, Lissamine Green B, parthenogenetic activation, mass spectrometry.

\section{Introduction}

Oocytes quality has a significant influence on the success of in vitro maturation (IVM), fertilization (IVF), embryo development and possible implantation (Goto et al., 1988; Sirard et al., 2006; Hoshino, 2018; Murin et al., 2019). Lower oocyte quality and occurrence of morphological anomalies are related a lower rate of IVM, IVF and IVC, which means, that oocyte quality is a key attribute of effective in vitro manipulations and treatment of infertility. This fact is a reason why oocyte collection is based on a strictly qualitative assessment of the current state of oocytes and embryos (Vassena et al., 2003; Krisher, 2004).

*Corresponding author: fstrejcek@ukf.sk

Received: October 22, 2020. Accepted: November 9, 2020.

Financial support: This work was supported by the projects "EXCELLENCE in molecular aspects of the early development of vertebrates",

CZ.02.1.01/0.0/0.0/15_003/0000460 from the Operational Programme Research, Development and Education and by the Danish Council for Independent Research/Natural Sciences (FNU) 8021-00048B, by the Slovak Reasearch and Development Agency under the Contract no. SK-FR-19-0010 and was co-funded by the projects VEGA 1/0001/19, 1/0167/20, FVMS-IPR-02 with decision No. 2020-2090/4 and by the European Community under project No. 26220220180: Building Research Centre "Agrobiotech".

Conflicts of interest: The authors have no conflict of interest to declare.

(c) (i) Copyright (c) The Author(s). This is an Open Access article distributed under the terms of the Creative Commons Attribution License, which permits unrestricted use, distribution, and reproduction in any medium, provided the original work is properly cited. 
Oocyte quality can determine the probability of success of in vitro techniques. Nevertheless, objective and non-invasive methods used for evaluation of oocyte quality have been a problematic for decades. The right approach to evaluation can provide valuable information for the selection of oocytes with higher developmental competence and may maximize the success of embryo development (Wang and Sun, 2007; Mtango et al., 2008).

The most integrated and easiest way to evaluate oocyte quality is the morphological determination of the entire cumulus-oocytes complex (Combelles and Racowsky, 2005). Morphological evaluation is a traditional method based on morphological classification of the size and shape of cumulus-oocyte complexes (COCs), polar bodies (PBs), oolemma, zona pellucida and meiotic spindles (Sun and Nagai, 2003; Wang and Sun, 2007; Lasiene et al., 2009). Morphological evaluation provides valuable information for the selection of COCs with high quality, but in general, this technique is still subjective (Coticchio et al., 2004; Wang and Sun, 2007; Lasiene et al., 2009).

Various non-invasive methods for oocyte quality evaluation have been practiced and suggested. The most used non-invasive methods are for example propidium iodide or Brilliant cresyl blue staining (Murin et al., 2019). These methods have got a lot of positives and negatives. Due this fact, Lissamine Green B (LB) could be very elegant solution of these negatives. Lissamine Green B is a non-toxic and synthetic stain composed of an organic acid dye with two aminophenyl groups (Kim et al., 2009) and was already used for the selection of porcine oocytes (Dutta et al., 2016). This vital staining can detect cell damage, which means that LB diffuses through the damaged membrane. LB is also used in ophthalmology to evaluate the integrity of the ocular membrane. In reproductive medicine and embryotechnology, LB is a fast, cheap, and objective way to visualize membrane damage in oocytes used for embryo production in vitro.

Under in vitro conditions, meiotic division is reinitiated after in vitro fertilization or parthenogenetic activation. Nowadays, parthenogenetic activation is a modern tool, in which embryogenesis begins without previous sperm fertilization, which means that this method eliminates the influence of sperm and embryogenesis depends exclusively on the oocyte quality. The parthenogenetic activation of the oocyte can be initiated by various physical, mechanical, and chemical stimuli such as ethanol, ionomycin, ionophore, or direct electrical impulses (Alberio et al., 2001; Lane et al., 2002).

Electrochemical activation is based on pore formation in the oocyte membrane, which can increase levels of intracellular $\mathrm{Ca}^{2+}$ due to the influx of extracellular $\mathrm{Ca}^{2+}$ from the activation medium. Chemical activation is based on a combination of ionomycin and 6-DMAP (Alberio et al., 2001; Bing et al., 2001; Prochazka et al., 2011). Ionomycin can be characterized as a selective ionophore, which can bind intracellular $\mathrm{Ca}^{2+}$ and 6-DMAP as an inhibitor of maturation promoting factors (MPF) and mitogen-activated proteinkinase (MAPK) activity, which leads to the successful formation of parthenogenetic embryos (Machaty and Prather, 1998; Alberio et al., 2001; Bing et al., 2001; Yin et al., 2002; Prochazka et al., 2011).

The aim of this study was to determine the differences between two methods of the assessment of oocytes quality based on Lissamine Green B (LB) staining and the morphological evaluation. We decided to evaluate the effectiveness of electrochemical and chemical parthenogenetic activation and evaluated the applicability of LB staining of cumulus-oocyte complexes (COCs) as a non-invasive method for predicting the maturational and developmental competence of porcine oocytes cultured in vitro.

\section{Materials and methods}

Chemicals, culture media and all supplements were purchased from Sigma Chemical Co., AppliChem unless otherwise stated. Media were freshly prepared, pre-warmed at $38.5^{\circ} \mathrm{C}$ and filtrated with $0.2 \mu \mathrm{m}$ Whatman membrane filter directly before use.

Our experiments were based on a comparison of two methods of parthenogenetic activation. After evaluating the success of parthenogenetic activation, we focused on comparison of the morphological assessment of oocyte quality and the vital assessment by 
Lissamine Green B staining, where we evaluated MII phase achieving, cleavage rate, blastocyst rate and proteomic profiling.

\section{Collection of oocytes}

Porcine ovaries were collected at a local slaughterhouse. The ovaries were transported within one hour to the laboratory in thermos at $38^{\circ} \mathrm{C}$ and washed three times in pre-warmed phosphate-buffered saline solution (PBS) supplemented with $0.4 \%$ (wt/vol) bovine serum albumin (BSA; Merck; Darmstadt, Germany), $0.34 \mathrm{mM}$ glucose, $5.5 \mathrm{mM}$ pyruvate, $50 \mathrm{IU} / \mathrm{mL}$ penicillin and $50 \mu \mathrm{g} / \mathrm{mL}$ streptomycin. Oocytes with follicular fluid were aspirated from ovarian follicles using a needle and $5 \mathrm{ml}$ syringe. Aspirates were collected in $15 \mathrm{~mL}$ Falcon tubes and allowed to settle for $20 \mathrm{~min}$ at room temperature. 2/3 of the supernatant was gently removed and the sediment was used for COC collection under a Nikon SMZ800N (Tokyo, Japan, 45x magnification) stereomicroscope. Cumulus-oocytes complexes were recovered, collected and washed three times in PBS (Sun et al., 2004).

\section{In vitro maturation (IVM) of oocytes}

After the evaluation of oocyte quality, COCs were washed three times in Dulbecco's modified Eagle's medium (DMEM supplemented with $10 \mathrm{IU} / \mathrm{mL}$ PMSG (Prospec, Israel) and hCG (Prospec, Israel), 50 ng/ mL EGF, 100 ng/mL IGF1 and 5 ng/ mL FGF). The DMEM medium was pre-warmed for 1 hour in a Petri dish. COCs were cultured and placed in groups of 30 in $500 \mu \mathrm{L}$ DMEM, for 44 hours at $38.5^{\circ} \mathrm{C}$ under $5 \% \mathrm{CO}_{2}$ in air.

\section{Parthenogenetic activation of oocytes}

After in vitro maturation, the collected oocytes were divided into two experimental groups and different methods of parthenogenetic activation were applied. The first experimental group of oocytes was activated electrochemically and the second chemically.

At the beginning of electrochemical activation, cumulus cells were removed with gentle pippeting with a $100 \mu \mathrm{L}$ micropipette without hyaluronidase. Denuded oocytes were washed in mPBS and cultivated for 4 hours in TL-HEPES $+\mathrm{Ca}^{+}$medium. After cultivation, the oocytes were washed in SOR 2 medium and activated with $38 \mathrm{~V}$ for $100 \mu \mathrm{s}$ in an electroporator (CF-150/B Electro-Cell Manipulator, Hungary). Subsequently, electrically activated oocytes were washed three times in porcine zygote medium 3 (PZM3) with 6-dimethylaminopurine (6-DMAP, 2mM) and cultured in groups of 30 in $500 \mu \mathrm{L}$ of PZM3 with 6-DMAP for 3 hours at $38.5{ }^{\circ} \mathrm{C}$ under $5 \% \mathrm{CO}_{2}$ in air (Yoshioka et al., 2002).

Chemical activation was based on the combination of ionomycin and 6-DMAP. Oocytes were denuded by gentle pipetting with a $100 \mu \mathrm{L}$ micropipette. After that, oocytes were washed twice in mPBS and activated in groups of 30 for $5 \mathrm{~min}$. with $5 \mu \mathrm{M}$ ionomycin. The activated oocytes were washed three times in the PZM3 medium with 2mM 6-DMAP and cultivated for 5 hours. After cultivation, oocytes were washed three times and cultured in the same medium for 5 hours at $38.5^{\circ} \mathrm{C}$ under $5 \% \mathrm{CO}_{2}$ in air (Prochazka et al., 2011).

\section{In vitro cultivation}

The activated oocytes were cultured in $50 \mu \mathrm{L}$ drops of PZM3 overlaid with mineral oil for 7 days at $38.5{ }^{\circ} \mathrm{C}$ with $5 \% \mathrm{CO}_{2}$ in air. Cleavage rate was evaluated $48 \mathrm{~h}$ after activation and blastocyst rate was observed after $168 \mathrm{~h}$ of in vitro cultivation. (Yoshioka et al., 2002). 


\section{Evaluation of oocyte quality}

After the comparison of parthenogenetic activations, we decided for chemical activation in our subsequent experiments, where COCs were evaluated using morphological criteria and LB staining.

\section{Morphological evaluation}

For further study only high-quality COCs with a homogenous, transparent and unfragmented ooplasm with more than two compact layers of cumulus cells were selected. The selected oocytes were divided into two groups, those selected by the morphological evaluation (control group) and those selected by the LB staining evaluation.

\section{LB evaluation}

The selected COCs were placed in groups of 30 for 10 min. in $500 \mu \mathrm{L} 0.5 \%$ LB at RT. Stained COCs were washed three times in mPBS (PBS $+0.4 \%$ bovine saline albumin-BSA) and observed under a Nikon SMZ800N stereomicroscope. After washing, the COCs were divided into two qualitative subgroups based on LB staining. We focused on detection of damaged cytoplasmic membrane, which was characterized by green stained ooplasm. Unstained (LB-) COCs with $0 \%$ stained cumulus cells were classified as high-quality COCs and stained (LB+) COCs with green ooplasm were designated as COCs with poor quality. In the LB+ group percentage of stained cumulus cells was not considered as an important marker (Figure 1) (Dutta et al., 2016).

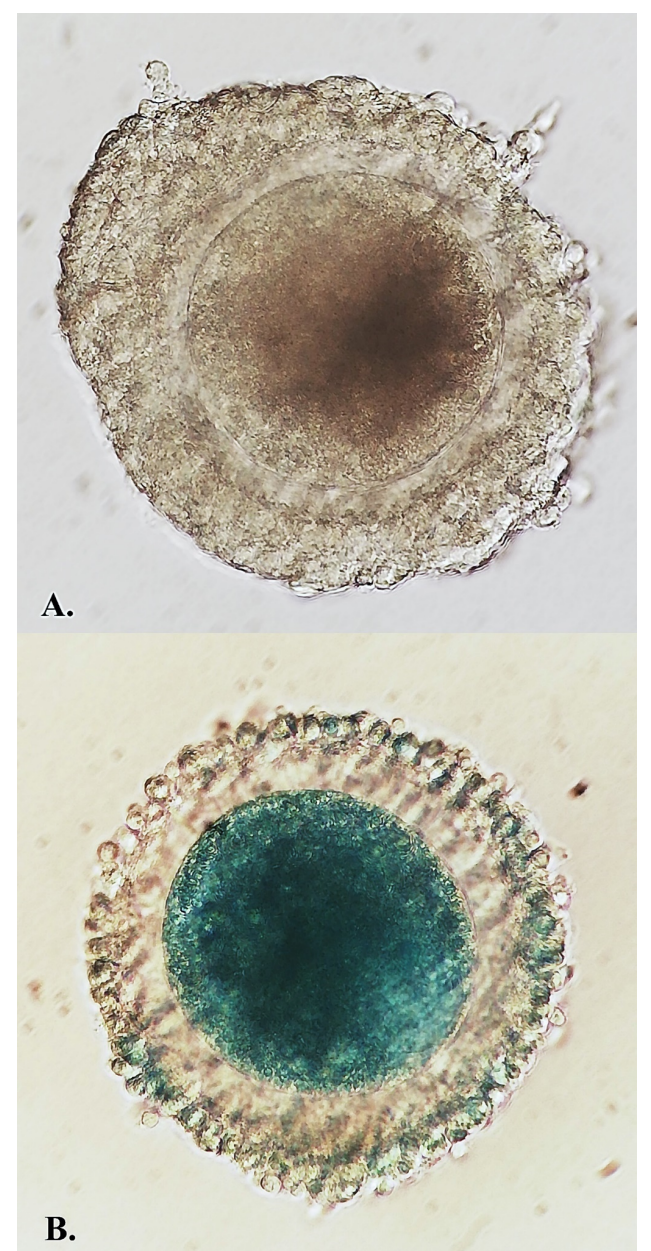

Figure 1. Classification of porcine oocytes after Lissamine Green B staining. (A) There is LB- oocyte, which represents high quality group; (B) There is LB+ oocyte, which represents low quality group (magnification X 400). 


\section{Sample preparation for proteomic profiling}

For the nano HPLC-Chip-MS/MS analysis, samples of 20 LB- and LB+ oocytes were lysed in $200 \mu \mathrm{L}$ of SDT lysis buffer containing 4\% SDS (w/v), $0.1 \mathrm{M} \mathrm{DTT}, 0.1 \mathrm{M} \mathrm{Tris} / \mathrm{HCl} \mathrm{pH} 7.6$ and protease inhibitors (1x Roche complete) by shaking for 1 hour at $37^{\circ} \mathrm{C}$. Immediately after lysis, samples were cooled down to $4{ }^{\circ} \mathrm{C}$ and centrifuged at $16000 \times \mathrm{g}$ for $5 \mathrm{~min}$. The supernatant was transferred to $3 \mathrm{kDa}$ molecular weight cut-off filter plates (Amicon Ultra-0.5 $\mathrm{ml} 3 \mathrm{~K}$, Millipore) and spun at $14000 \times \mathrm{g}$ for $40 \mathrm{~min}$. For the extraction of tryptic peptides from the complex protein mixture, a modified filter-aided sample preparation (FASP) protocol was used according to Wisniewski et al. (2009). Detergent removal by buffer exchange was performed in two sequential washes of filter plates with $200 \mu \mathrm{L}$ of $8 \mathrm{M}$ urea in $0.1 \mathrm{M} \mathrm{Tris} / \mathrm{HCl}$ $\mathrm{pH} 8.5$ (UA), each followed by centrifugation at $14000 \times \mathrm{g}$ for $40 \mathrm{~min}$. Flow-through was removed from the collection tubes. Proteins were then alkylated in $100 \mu \mathrm{L}$ of $0.05 \mathrm{M}$ iodoacetamide in UA by mixing at $600 \mathrm{rpm}$ in a thermo-mixer for $1 \mathrm{~min}$ and incubating without mixing for $20 \mathrm{~min}$. After centrifugation at $14000 \times \mathrm{g}$ for $30 \mathrm{~min}$, two additional washes using $100 \mu \mathrm{L}$ of $0.05 \mathrm{M} \mathrm{NH}_{4} \mathrm{HCO}_{3}$, with $10 \mathrm{~min}$ at $14000 \mathrm{xg}$ after each wash, were included to remove excess urea and prepare the proteins for digestion. Protein digestion was performed by adding $2 \mu \mathrm{g}$ of trypsin (Trypsin Gold, Promega) in $0.05 \mathrm{M} \mathrm{NH}_{4} \mathrm{HCO}_{3}$ and incubating at $37^{\circ} \mathrm{C}$ overnight. Peptides were recovered by spinning the filter plates upside down at $14000 \times \mathrm{g}$ for $40 \mathrm{~min}$. The mixture was vacuum dried and the pellet was resuspended in $50 \mu \mathrm{L}$ of mobile phase ( $97 \%$ water, $3 \%$ acetonitrile).

\section{Protein identification by tandem mass spectrometry (nano HPLC-chip-MS/MS)}

The tryptic peptides were loaded into the $40 \mathrm{~nL}$ enrichment column (filled with Zorbax SB C18, $5 \mu \mathrm{m}$ ) of an Agilent 1260 ChipCube MS Interface by an Agilent 1260 Capillary Pump (Agilent Technologies, Palo Alto, USA). After loading and desalting of the sample in the chip enrichment column peptides were eluted in a forward flush and transferred to the analytical column at a flow rate of $600 \mathrm{~nL} / \mathrm{min}$ by an Agilent 1260 Nano pump with an increasing percentage of organic phase. The mobile phase consisted of an aqueous (A) or acetonitrile (B) solution of formic acid $(0.1 \%, v / v)$. The chromatographic separation was achieved with a gradient elution using the following sequence: $0 \mathrm{~min}, 3 \% \mathrm{~B} ; 2 \mathrm{~min}, 3 \% \mathrm{~B} ; 25 \mathrm{~min}, 50 \% \mathrm{~B} ; 30$ min, 50\% B; $35 \mathrm{~min}, 95 \% \mathrm{~B} ; 40 \mathrm{~min}, 95 \% \mathrm{~B} ; 45 \mathrm{~min}, 3 \%$ B followed by a post-period of $10 \mathrm{~min}$ for column re-equilibration. The analytical column was connected to a Q-TOF Agilent 6500 Series mass spectrometer. A $1750 \mathrm{~V}$ tension was applied to the electrodes of the nanospray ionization chamber. High-purity nitrogen $(99.99999 \%)$ was used as the collision gas and the collision energy was settled as a function of the precursor ion mass and charge. MS/MS spectra were acquired by automatic switching between MS and MS/MS mode (auto MS/MS mode). Acquired MS/MS data were analyzed using the SpectrumMill search engine (Agilent Technologies, Palo Alto, USA). Database searches were performed against the self-built database from the UniProt porcine proteome (UP000008227). The following autovalidation criteria of SpectrumMill software were used to validate the identified proteins and peptides: the minimum score for proteins was 10 , minimum scores for spectra resulting from fragmentation of $2+, 3+$, and $4+$ precursor ions were 8,7 and 9 , respectively, with a scored peak intensity value of at least $60 \%$.

\section{Assessment of in vitro oocyte maturation}

After 48 hours of in vitro maturation, cumulus cells were removed from oocytes. We prepared microscope slides, where two strips of grease were placed approximately $1.5 \mathrm{~cm}$ apart. The oocytes were transferred to the space between strips, covered with a cover glass and fixed for 24 hours in a 3:1 mixture of ethanol (96\%) and acetic acid. After fixation, the oocytes were stained with lacmoid and the success rate of in vitro maturation was evaluated with phase-contrast microscope (Laurincik et al., 1994). 


\section{Statistical analysis}

Our data were expressed as means \pm standard deviation of the mean (SD). We evaluated our data by one-way analysis of variance (ANOVA single factor) and t-test (SigmaPlot 12.0, London, UK), where a probability of $<0.05$ was considered to be statistically significant.

\section{Ethical standards}

The authors assert that all procedures contributing to this work comply with the ethical standards of the relevant national and institutional guides on the care and use of laboratory animals.

\section{Results}

The COCs obtained from the local slaughterhouse were divided into several experimental groups and used for our experiments, which based on the comparison of different techniques of parthenogenetic activation, LB staining and proteomic profiling.

\section{In vitro maturation}

In total 268 COCs were divided into 3 experimental groups: the control group (CG), LB+ group and LB- group. The evaluation of proper in vitro maturation was based on the presence of condensed chromosomes in an equatorial position. The maturation rate of the control group, which consisted of morphologically graded COCs, was 74.03\%. In the LB+ group it was $22.80 \%$ and in LB- it was $82.24 \%$. These data showed significant differences between the control group and LB+ group and between the LB+ and LB- groups (Table 1).

Table 1. Maturation ability of porcine oocytes treated with LB in vitro. Five replicates of this experiment were performed. In brackets, numbers of oocytes are stated. Within a column, values with different small letters $(a, b)$ are significantly different with $\mathrm{P}<0.05$.

\begin{tabular}{ccc} 
Experimental group & No. of oocytes & \% of oocytes in MII \\
\hline Control & 104 & $74.03 \pm 6.18(77)^{\mathrm{a}}$ \\
\hline LB+ & 57 & $22.80 \pm 8.03(13)^{\mathrm{b}}$ \\
\hline LB- & 107 & $82.24 \pm 1.02(88)^{\mathrm{a}}$ \\
\hline
\end{tabular}

\section{Proteomic evaluation of LB- and LB+ oocytes}

In this part of the study, we compared the protein patterns of LB- and LB+ pig oocytes using the off-gel approach in combination with tandem mass spectrometry. Based on the morphological observations (chromosome condensation) and Lissamine Green B staining, the oocytes were divided into two different qualitative groups where LB- oocytes were considered to be the high-quality oocytes with the highest maturation rate (82\%). Despite difficulties with obtaining a sufficient amount of material to identify low-abundance proteins by mass spectrometry, we were able to unambiguously discern the differences $(P<0.05)$ between the proteomic profiles of LB- and LB+ oocytes. In the LB- oocytes, we were able to identify 67 proteins, whereas in the LB+ group we could identify only 19 proteins (Figure 2). Our proteomic analysis also identified a selection of proteins that appeared to be differentially expressed in each group of analysed oocytes. Oocytes of the LB- group exhibited an increased variability of proteins involved in RNA pol II- and RNA pol III-mediated transcription regulation, proteosynthesis and protein folding. LB+ oocytes lacked the majority of transcription-related proteins and mostly contained enzymes or proteins from the zona pellucida (Table 2). 
Table 2. List of 25 selected proteins from Spectrum Mill - Protein peptide/Summary involved in fertilization, transcription and translation processes sorted by function/activity.

\begin{tabular}{|c|c|c|c|c|c|}
\hline $\begin{array}{l}\text { Protein } \\
\text { function }\end{array}$ & $\begin{array}{l}\text { Accession } \\
\text { number* }\end{array}$ & Protein name & $\begin{array}{c}M W \\
(k D a)\end{array}$ & LB- oocytes & LB+ oocytes \\
\hline \multirow{3}{*}{ 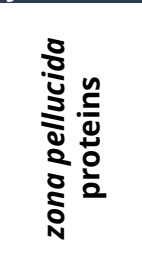 } & P42099 & $\begin{array}{l}\text { Zona pellucida sperm-binding } \\
\text { protein } 2\end{array}$ & 79,67 & + & + \\
\hline & P42098 & $\begin{array}{l}\text { Zona pellucida sperm-binding } \\
\text { protein } 3\end{array}$ & 46,20 & + & + \\
\hline & Q07287 & $\begin{array}{c}\text { Zona pellucida sperm-binding } \\
\text { protein } 4\end{array}$ & 59,29 & + & + \\
\hline \multirow{5}{*}{ 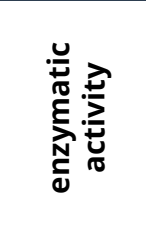 } & A0A287A1A8 & Acyl-coenzyme A oxidase & 66,47 & + & + \\
\hline & F1SUQ9 & Protein-arginine deiminase type- 6 & 76,87 & + & + \\
\hline & I3LBD5 & Serine/threonine-protein kinase 10 & 112,01 & + & + \\
\hline & Q9GL50 & Metalloreductase STEAP1 & 39,89 & + & - \\
\hline & F1SAN1 & $\begin{array}{c}\text { Caspase } 14, \text { apoptosis-related } \\
\text { cysteine peptidase }\end{array}$ & 27,70 & + & - \\
\hline \multirow{11}{*}{ 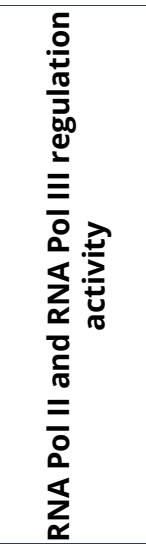 } & F2Z5J6 & Transcription initiation factor IIB & 34,81 & + & - \\
\hline & F1SPQ0 & $\begin{array}{c}\text { DNA-directed RNA polymerase } \\
\text { subunit beta }\end{array}$ & 122,58 & + & - \\
\hline & A0A287BRQ3 & ETS domain-containing protein & 55,80 & + & - \\
\hline & F1RUB7 & Transcriptional regulator Kaiso & 74,24 & + & - \\
\hline & A0A286ZZH2 & Storkhead box 1 & 110,23 & + & + \\
\hline & A6N8P5 & Multiprotein bridging factor 1 & 16,38 & + & - \\
\hline & A0A287B954 & $\begin{array}{l}\text { Transcriptional repressor p66-beta } \\
\text { isoform X1 }\end{array}$ & 65,21 & + & - \\
\hline & I3L8J9 & Zinc finger protein 77 & 58,76 & + & + \\
\hline & A0A286ZMX7 & $\begin{array}{l}\text { ANK_REP_REGION domain- } \\
\text { containing protein }\end{array}$ & 116,67 & + & - \\
\hline & A0A286ZJG5 & GYF domain-containing protein & 151,40 & + & - \\
\hline & I3LLE2 & GLTSCR1 domain-containing protein & 147,02 & + & - \\
\hline \multirow{6}{*}{ 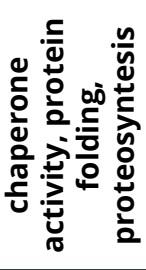 } & P63053 & Ubiquitin-60S ribosomal protein L40 & 14,71 & + & + \\
\hline & I3LQ79 & Major vault protein & 99,64 & + & + \\
\hline & F1SL22 & von Willebrand factor & 321,78 & + & + \\
\hline & A0A287BIL8 & $\begin{array}{l}\text { Endoplasmic reticulum chaperone } \\
\text { BiP }\end{array}$ & 72,22 & + & - \\
\hline & A0A287AQK7 & Heat shock protein HSP 90-alpha & 90,58 & + & - \\
\hline & A0A286ZK74 & RRM domain-containing protein & 25,28 & + & - \\
\hline
\end{tabular}

*Protein accession number referring to UniProt database. + detected, - undetected.

\section{NUMBER OF IDENTIFIED PROTEINS}

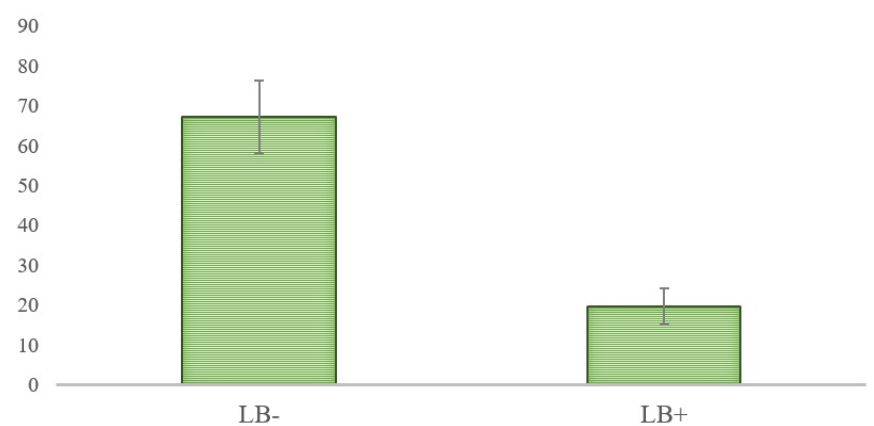

Figure 2. Differences in number of identified proteins from 20 LB- and LB+ oocytes with significance at level $\mathrm{P}<0.05$ for three independent proteomic analyses (sample preparation and protein identification by tandem mass spectrometry). 


\section{Electrochemical activation vs. chemical activation}

This experiment was carried out to compare electrochemical and chemical activation. In the first experimental group, activated by electrochemical activation $(n=147)$, the cleavage rate of embryos was $76.87 \%(n=113)$ and rate of blastocyst formation was $12.34 \%(n=14)$. In the second experimental group activated by chemical activation $(n=263)$, the cleavage rate was $79.85 \%(n=210)$ and rate of blastocyst formation was $17.14 \%(n=36)$. Although we observed small difference between two techniques of parthenogenetic oocyte activation, chemical activation was slightly more effective than electrochemical approach under our laboratory conditions, so we decided to utilise the chemical activation of LB groups (Table 3).

Table 3. Parthenogenetic activation of porcine oocytes after electrochemical and chemical activation. Five replicates of this experiment were performed. In brackets, numbers of oocytes or embryos are stated. Within a column, values with different small letter (a) are non-significally different with $\mathrm{P}<0.05$.

\begin{tabular}{cccc}
\multirow{2}{*}{ Experimental group } & No. of oocytes & \multicolumn{2}{c}{ \% of embryos development } \\
\cline { 3 - 4 } Electrochemical activation & 147 & $76.87 \pm 2.90(113)^{\mathrm{a}}$ & $12.34 \pm 2.09(14)^{\mathrm{a}}$ \\
\hline Chemical activation & 263 & $79.85 \pm 3.48(210)^{\mathrm{a}}$ & $17.14 \pm 1.06(36)^{\mathrm{a}}$ \\
\hline
\end{tabular}

\section{Effect of vital staining during embryogenesis}

The cleavage rate of the control group was $80.20 \%$ ( $n=158)$, in the LB+ group it was $16.66 \%$ $(n=12)$ and in the LB- group it was $84.32 \%(n=258)$. Significant differences were observed between the LB- group and LB+ group $(\mathrm{P}<0.05)$ and also between the control group and LB+ group $(\mathrm{P}<0.05)$. The highest blastocyst developmental rate was detected in the LB- group, where it was $28.68 \%(n=74)$. In the control group, the blastocyst rate was $20.89 \%(n=33)$ and in the $L B+$ group it was $8.33 \%(n=1)($ Table 4$)$. A significant difference was identified between the $L B$ - group and $L B+$ group $(P<0.05)$ and between the $L B+$ group and the control group $(P<0.05)$.

Table 4. Chemical activation of porcine oocytes treated with LB in vitro. Five replicates of this experiment were performed. In brackets, numbers of oocytes or embryos are stated. Within a column, values with different small letters $(a, b)$ are significantly different with $\mathrm{P}<0.05$.

\begin{tabular}{cccc} 
Experimental group & No. of oocytes & \multicolumn{2}{c}{ \% of embryos development } \\
\cline { 2 - 4 } Control & 197 & $80.20 \pm 2.83(158)^{\mathrm{a}}$ & $20.89 \pm 2.44(33)^{\mathrm{a}}$ \\
\hline LB+ & 72 & $16.66 \pm 4.92(12)^{\mathrm{b}}$ & $8.33 \pm 8.25(1)^{\mathrm{b}}$ \\
\hline LB- & 306 & $84.32 \pm 0.91(258)^{\mathrm{a}}$ & $28.68 \pm 1.72(74)^{\mathrm{a}}$ \\
\hline
\end{tabular}

\section{Discussion}

Oocyte quality is one of the key factors, which influences the success of embryo production in vitro. Oocyte quality can be characterized as a summary of individual and comprehensive assessments.

In this study, the determination of oocyte quality was done by LB staining as a noninvasive selective method detecting the cells and membrane damage of porcine oocytes before in vitro maturation. LB was used back in 1990 for the detection of damage to reticuloendothelial cells. In 2000, Kim et al. (2009) used LB for the in vitro staining of rabbit and human corneal epithelial cells and in 2015, Dutta et al. (2016) used LB for in vitro staining of porcine COC's. Based on these applications, we decided to test the effect of this non-toxic and non-carcinogenic dye on the in vitro maturation of oocytes and development of porcine embryos.

Our study is based on the comparison of the LB staining method with the routine morphological evaluation of oocytes and more comprehensive proteomic profiling. Our observations indicate that the evaluation of the oocytes based on LB staining is more effective 
than the morphological evaluation of oocyte quality. Under our laboratory conditions, we managed to optimize the cultivation and maturation of porcine oocytes. Our results show that we achieved a $74.03 \%$ maturation success rate in the control group. In comparison with the control group, we can conclude that the LB- group achieved a higher maturation rate (82.24\%) than both the control group (74.03\%) and LB+ group (22.80\%). Our results can be compared with Dutta et al. (2016), who focused on the evaluation of cumulus cells by Lissamine Green B. In Dutta et al. (2016) successful maturation rate was reached $79.9 \%$ in A grade group, which is very similar to our control group (74.03\%). With porcine A grade oocytes (high quality oocytes after LB staining), the successful maturation rate reached $84.70 \%$, which is almost identical to our LB- oocytes (82.24\%). Their study also observed a higher competence of $\mathrm{C}$ grade group (lower quality after LB staining) to reach MII (62.26\%), which is significantly different as our result in LB+ group (22.80\%). In Dutta et al. (2016), very similar differences were observed after parthenogenetic activation too. Based on the results, we can say that the detection of membrane damage leads to a significant reduction in oocyte developmental potential, which is more important than the detection of damaged cumulus cells.

Vital selection based on LB staining can be compared with vital selection by Brilliant cresyl blue (BCB) staining. With porcine BCB+ oocytes (high quality), Egerszegi et al. (2010) reported that after 44 hours of in vitro cultivation, the successful maturation rate reached $81.6 \%$, which is almost identical to our LB- oocytes. Their study also observed a significantly higher competence of $\mathrm{BCB}+$ oocytes to reach $\mathrm{MII}$ than $\mathrm{BCB}$ - oocytes, which also correlates with our results (LB- $82.24 \%$ vs. LB+ $22.80 \%$ ).

Additionally, the results achieved by LB staining fully correspond with our proteomic evaluation of porcine oocytes. Motivated by relatively weak knowledge about mammalian oocyte maturation in this field of research, we decided to utilise a proteomic approach to identify proteins that are differentially expressed during porcine oocyte maturation and thus support our preceding results (LB staining). Due to the lack of sufficient biological material (LB+ oocytes), the off-gel proteomic approach was applied, in which the whole protein extract without any further separation was analysed by tandem mass spectrometry. Also, a unique LC-based nano HPLC-chip workflow was followed to minimize the loss of analysed material. In the complete list of identified proteins isolated from LB- $(n=67)$ and LB+ $(n=19)$ oocytes, we selected 25 proteins important for fertilization, transcription, translation and posttranslational (protein folding) processes. Except for zona pellucida sperm-binding proteins ( 2 , 3 and 4), crucial for sperm binding, induction of the acrosome reaction and preventing postfertilization polyspermy, we observed that oocytes of the LB- group exhibit an increased variability of proteins $(n=22)$ involved in gene expression processes compare to LB+ oocytes $(n=6)$. With the LB+ oocytes, we may suppose that these absent proteins were not expressed in oocytes at the time of evaluation or more likely that their amounts were under the detection limit of the instruments we used. These differences in the protein composition of qualitatively distinct oocytes (LB- vs. LB+ oocytes) correspond to those observed by Ellederova et al. (2004) in porcine GV, MI and MII stage oocytes. Based on the assumption that the quality and thus the fertilization competence of oocytes rises from the GV to the MII stage, the comparative proteomic approach was used to analyze the oocytes at different stages of maturation to characterize the candidate proteins which were differentially expressed during in vitro maturation. The results of their proteomic evaluation of porcine oocytes showed that some of the identified proteins were more abundantly expressed in high-quality MII-stage oocytes than in GV oocytes. Similar results were achieved by the team of Vitale et al. (2007) and Virant-Klun et al. (2016), where the protein profiles of oocytes (mouse, human) during in vitro maturation were studied. In both cases, the proteomic analysis of GV and MII-stage oocytes identified a selection of unique proteins that appeared to be differently regulated during oocyte maturation.

We achieved a high cleavage rate in both types of parthenogenetic activations, but the rates of blastocysts were different. Our results indicated that better embryo development was obtained via chemical activation with ionomycin and 6-DMAP. A similar result was observed by Che et al. (2007) (71\% cleavage vs. 32\% blastocysts). Prochazka et al. (2011) reported a successful cleavage rate $73 \%$ and blastocyst rate of $38 \%$, which is similar to our 
results. Their study also confirmed the beneficial effect and high rate of blastocysts obtained by the combination of ionomycin and 6-DMAP.

With the chemical activation of LB oocytes, our data showed significant differences between the LB+ and LB- group. In vitro maturation and in vitro parthenogenetic activation of LB- oocytes were more successful than the LB+ group.

\section{Conclusions}

In conclusion, our study indicates that chemical activation combined with LB staining can result in effective production of parthenogenetic porcine embryos. The evaluation of the oocytes quality based on Lissamine Green B staining is vital, cheap and quick selecting method and it is slightly more probative than the morphological evaluation of oocyte quality. From the proteomics point of view, the differentially regulated proteins acting during oocyte in vitro maturation may represent a group of promising biomarkers of oocyte maturation and quality.

\section{References}

Alberio R, Zakhartchenko V, Motlik J, Wolf E. Mammalian oocyte activation: lessons from the sperm and implications for nuclear transfer. Int J Dev Biol. 2001;45(7):797-09. http://dx.doi.org/10.1292/jvms.150658. PMid:11732839.

Bing Y, Nagai T, Rodrìguez-Martinez H. Effects of cysteamine, fsh and estradiol-17beta on in vitro maturation of porcine oocytes. Theriogenology. 2001;55(4):867-76. http://dx.doi.org/10.1016/S0093691X(01)00449-6. PMid:11291910.

Che L, Lalonde A, Bordignon V. Chemical activation of parthenogenetic and nuclear transfer porcine oocytes using ionomycin and strontium chloride. Theriogenology. 2007;67(7):1297-304. http://dx.doi.org/10.1016/j.theriogenology.2007.02.006.

Combelles CM, Racowsky C. Assessment and optimization of oocyte quality during assisted reproductive technology treatment. Semin Reprod Med. 2005;23(3):277-84. http://dx.doi.org/10.1055/s-2005872456. PMid:16059834.

Coticchio G, Sereni E, Serrao L, Mazzone S, Iadarola I, Borini A. What criteria for the definition of oocyte quality? Ann N Y Acad Sci. 2004;1034(1):132-44. http://dx.doi.org/10.1196/annals.1335.016. PMid:15731306.

Dutta R, Li S, Fischer K, Kind A, Flisikowska T, Flisikowski K, Rottmann O, Schnieke A. Non-invasive assessment of porcine oocyte quality by supravital staining of cumulus.oocyte complexes with lissamine green B. Zygote. 2016;24(3):418-27. http://dx.doi.org/10.1017/S0967199415000349. PMid:27172057.

Egerszegi I, Alm H, Ratky J, Heleil B, Brussow KP, Torner H. Meiotic progression, mitochondrial features and fertilization characteristics of porcine oocytes with different G6PDH activities. Reprod Fertil Dev. 2010;22(5):830-8. http://dx.doi.org/10.1071/RD09140. PMid:20450835.

Ellederova Z, Halada P, Man P, Kubelka M, Motlik J, Kovarova H. Protein patterns of pig oocytes during in vitro maturation. Biol Reprod. 2004;71(5):1533-9. http://dx.doi.org/10.1095/biolreprod.104.030304. PMid:15229143.

Goto K, Kajihara Y, Kosaka S, Koba M, Nakanishi Y, Ogawa K. Pregnancies after co-culture of cumulus cells with bovine embryos derived from in vitro fertilization of in vitro matured follicular oocytes. J Reprod Fertil. 1988;83(2):753-8. http://dx.doi.org/10.1530/jrf.0.0830753. PMid:3411565.

Hoshino Y. Updating the markers for oocyte quality evaluation: intracellular temperature as a new index. Reprod Med Biol. 2018;17(4):434-41. http://dx.doi.org/10.1002/rmb2.12245. PMid:30377396.

Kim TJ, Laufer LR, Hong SW. Vitrification of oocytes produces high pregnancy rates when carried out in fertile women. Fertil Steril. 2009;83(2):753-8. http://dx.doi.org/10.1016/j.fertnstert.2008.12.094. PMid:19217099.

Krisher RL. The effect of oocyte quality on development. J Anim Sci. 2004;82:E14-23. http://dx.doi.org/10.2527/2004.8213_supplE14x. PMid:15471793. 
Lane M, Maybach JM, Gardner DK. Addition of ascorbate during cryoperservation stimules subsequent embryo development. Hum Reprod. 2002;17(10):2686-93. http://dx.doi.org/10.1093/humrep/17.10.2686. PMid:12351549.

Lasienë K, Vitkus A, Valanèiûtë A, Lasys V. Morphological criteria of oocyte quality. Medicina (Kaunas). 2009;45(7):509-15. http://dx.doi.org/10.3390/medicina45070067. PMid:19667744.

Laurincik J, Rath D, Niemann H. Differences in pronucleus formation and first cleavage following in vitro fertilization between pig oocytes matured in vivo and in vitro. J Reprod Fertil. 1994;102(2):277-84. http://dx.doi.org/10.1530/jrf.0.1020277. PMid:7861378.

Macháty Z, Prather RS. Strategies for activating nuclear transfer oocytes. Reprod Fertil Dev. 1998;10(78):599-613. http://dx.doi.org/10.1071/RD98048. PMid:10612466.

Mtango NR, Potireddy S, Latham KE. Oocyte quality and maternal control of development. Int Rev Cell Mol Biol. 2008;268:223-90. http://dx.doi.org/10.1016/S1937-6448(08)00807-1. PMid:18703408.

Murin M, Strejcek F, Bartkova A, Morovic M, Benc M, Prochazka R, Lucas-Hahn A, Pendovski L, Laurincik J. Intranuclear characteristics of pig oocytes stained with brilliant cresyl blue and nucleologenesis of resulting embryos. Zygote. 2019;27(4):232-40. http://dx.doi.org/10.1017/S0967199419000352. PMid:31397243.

Procházka R, Petlach M, Nagyova E, Nemcova L. Effect of epidermal growth factor-like peptides on pig cumulus cell expansion, oocyte maturation, and acquisition of developmental competence in vitro: comparison with gonadotropins. Reprod. 2011;141(4):425-35. http://dx.doi.org/10.1530/REP-10-0418

Sirard MA, Richard F, Blondin P, Robert C. Contribution of the oocyte to embryo quality. Theriogenology. 2006;65(1):126-36. http://dx.doi.org/10.1016/j.theriogenology.2005.09.020. PMid:16256189.

Sun QY, Nagai T. Molecular mechanisms underlying pig oocyte maturation and fertilization. J Reprod Dev. 2003;49(5):347-59. http://dx.doi.org/10.1262/jrd.49.347. PMid:14967910.

Sun XS, Liu Y, Yue KZ, Ma SF, Tan JH. Changes in germinal vesicle (GV) chromatin configurations during growth and maturation of porcine oocytes. Mol Reprod Dev. 2004;69(2):228-34. http://dx.doi.org/10.1002/mrd.20123. PMid:15293225.

Vassena R, Mapletoft RJ, Allodi S, Singh J, Adams GP. Morphology and developmental competence of bovine oocytes relative to follicular status. Theriogenology. 2003;60(5):923-32. http://dx.doi.org/10.1016/S0093-691X(03)00101-8. PMid:12935869.

Virant-Klun I, Leicht S, Hughes C, Krijgsveld J. Identification of maturation-specific proteins by single-cell proteomics of human oocytes. Mol Cell Proteomics. 2016;15(8):2616-27. http://dx.doi.org/10.1074/mcp.M115.056887. PMid:27215607.

Vitale AM, Calvert MEK, Mallavarapu M, Yurttas P, Perlin J, Herr J, Coonrod S. Proteomic profiling of murine oocyte maturation. Mol Reprod Dev. 2007;74(5):608-16. http://dx.doi.org/10.1002/mrd.20648. PMid:17044029.

Wang Q, Sun QY. Evaluation of oocyte quality: morphological, cellular and molecular predictors. Reprod Fertil Dev. 2007;19(1):1-12. http://dx.doi.org/10.1071/RD06103. PMid:17389130.

Wiśniewski JR, Zougman A, Nagaraj N, Mann M. Universal sample preparation method for proteome analysis. Nat Methods. 2009;6(5):359-62. http://dx.doi.org/10.1038/nmeth.1322. PMid:19377485.

Yin XJ, Tani T, Yonemura I, Kawakami M, Miyamoto K, Hasegawa R, Kato Y, Tsunoda Y. Production of cloned pigs from adult somatic cells by chemically assisted removal of maternal chromosomes. Biol Reprod. 2002;67(2):442-6. http://dx.doi.org/10.1095/biolreprod67.2.442. PMid:12135879.

Yoshioka K, Suzuki C, Tanaka A, Anas IMK, Iwamura S. Birth of piglets derived from porcine zygotes cultured in a chemically defined medium. Biol Reprod. 2002;66(1):112-9. http://dx.doi.org/10.1095/biolreprod66.1.112. PMid:11751272.

\section{Author contributions}

AB: LB experiments, Writing - original draft, Writing - review \& editing; MM: Proteomic analysis, Writing - original draft, Writing - review \& editing; FS: Conceptualization, Writing - original draft, Writing - review \& editing; MM: Writing - review \& editing, Formal analysis; MB: Formal analysis, Writing review \& editing; FPP: Formal analysis, Writing - review \& editing; JL: Supervision, Writing - review \& editing. 